\title{
Synthesis, Spectral and Electrochemical Studies of Complex of Uranium(IV) with Pyridine-3-Carboxylic Acid
}

\author{
Misbah Nazir ${ }^{1^{*}}$, Iftikhar Imam Naqvi \\ ${ }^{1}$ Department of Chemistry, Federal Urdu University of Arts, Science and Technology, Gulshan Campus, Karachi, Pakistan \\ ${ }^{2}$ National Core Group in Chemistry, H.E.J Research Institute of Chemistry, University of Karachi, Karachi, Pakistan \\ Email: "nazir_misbah@yahoo.com
}

Received February 4, 2013; revised March 5, 2013; accepted March 17, 2013

\begin{abstract}
The investigation of complexation of uranium with biological active ligands is vital for understanding uranium speciation in biosystems. A number of studies have been undertaken for investigating the complexation of uranium in its (VI) oxidation states but similar investigations pertaining to the interaction of uranium, in lower oxidation states, with biological ligands is scarce. The aim of the work is to bridge this gap and studies have been carried out to determine the coordination pattern of pyridine-3-carboxylic acid with uranium(IV). Semi-micro analysis, spectro-analytical techniques, magnetic susceptibility and cyclic voltammetry have been employed for the characterization of the synthesized complex.
\end{abstract}

Keywords: Uranium(IV); Pyridine-3-Carboxylic Acid; Spectroscopic Techniques; Magnetic Susceptibility; Electrochemical Studies

\section{Introduction}

The presence of uranium in the crust of the earth is about 2 parts per million and among the elements, ranks about 48th in natural abundance in crust's rocks. It is also present in seawater, though in very small concentrations of about $3.3 \mathrm{ng} / \mathrm{mL}$, but distributed uniformly all over the world $[1,2]$. We cannot ignore the importance of research on behavior of this metal in biosystems. A score of publications have been surfaced on the complexation tendencies of uranium(VI) with different biological ligands [3, 4]. The aim of this work is to examine the interaction of uranium, in its (IV) oxidation state, with a ligand of biological significance i.e. pyridine-3-carboxylic acid (Figure 1). Pyridine-3-carboxylic acid (also known as Nicotinic acid) is an essential vitamin. It possesses two potential ligating groups; pyridine ring nitrogen and carboxyl oxygen. But when it acts as a monodentate ligand, bonding may occur through either of these sites [5]. Different techniques have been employed to characterize the newly synthesized complex of uranium(IV) with pyridine-3-carboxylic acid.

\section{Experimental}

\subsection{Materials and Method}

Uranium(VI) stock solution, prepared by dissolving ura-

${ }^{*}$ Corresponding author.<smiles>O=C(O)c1cccnc1</smiles>

Figure 1. Pyridine 3-carboxylic acid.

nyl nitrate hexahydrate, (B.D.H) (1.255 g, $2.5 \mathrm{mmol})$ in $0.2 \mathrm{M} \mathrm{HCl}(25 \mathrm{ml})$, was reduced to uranium(IV) by catalytic hydrogenation, in the presence of platinized alumina (Aldrich) as a catalyst [6]. The complex was prepared by mixing pyridine-3-carboxylic acid $(0.6155 \mathrm{~g}, 5 \mathrm{mmol})$ to that of metal ion solution whose concentration was predetermined. Small volume of $\mathrm{NaOH}(1 \mathrm{M})$ solution was then added to the reacting mixture to adjust the $\mathrm{pH}$ between 4.5 and 5. It is the $\mathrm{pH}$ range where precipitation of the desired complex occurs. The precipitates of the complex thus formed were filtered through whatmann 542 filter paper and washed with deionized water and $99 \%$ absolute alcohol. The residue was dried over silica gel. $\mathrm{U}(\mathrm{Nic})_{2}(\mathrm{OH})_{2} \cdot 2 \mathrm{H}_{2} \mathrm{O}$ mol.wt. $552.22 \mathrm{~g} / \mathrm{mol}$. Found: C, 26.09; H, 2.48; N, 5.55; U, 42.99; Anal. Calcd: C, 26.07; H, 2.53; N, 5.07; U, 43.09, Yield (75.39\%).

\subsection{Characterization}

The complex was analyzed for its uranium(IV), C, H, N 
and $\mathrm{S}$ contents. uranium(IV) analysis was performed by means of a volumetric titration with $\mathrm{K}_{2} \mathrm{Cr}_{2} \mathrm{O}_{7}$, using barium salt of diphenylamine sulphonic acid as an indicator [6]. UV-Visible spectra of free metal and metal plus ligand solutions were taken using Shimadzu UV-160A UVVis Spectrophotometer. IR spectra of complex and the ligand were recorded for the wavenumber range of 4000 $400 \mathrm{~cm}^{-1}$ using IR Prestige-21 FTIR spectrophotometer. IR assignments of pure ligand were also confirmed from literature. The spectra were recorded in association with $\mathrm{KBr}$ through the discs, prepared for this purpose. Sherewood Scientific Magnetic Susceptibility Balance (M.S.B) was used to measure magnetic susceptibility values of the complex in solid state. Cyclic voltammetric measurements were carried out on Electrochemical Analyzer/workstation, CHI $660 \mathrm{C}$, under nitrogen atmosphere at $302 \mathrm{~K}$. A platinum working electrode, a platinum-wire counter electrode and an $\mathrm{Ag} / \mathrm{AgCl}$ reference electrode were used in a single three electrode cell.

\section{Results and Discussion}

\subsection{UV-Visible Measurements}

Figure 2 depicts a comparative illustration of UV-Visible absorption spectra of free uranium(IV) solution and a solution of complexed uranium(IV) with pyridine-3-carboxylic acid. The pattern of absorption of visible radiations remains same with the slight bathochromic shift. However, the absorption intensity of metal in the presence of the ligand increases. The value of molar absorptivity coefficient for the synthesized complex, calculated from the data of UV-Visible absorption of the complex is tabulated in Table 1. The mole ratio plot at different wave lengths (Figure 3) gives an evidence of formation of the complex with 1:2 metal to ligand ratio.

The bathochromic shift for the bands at $644.0 \mathrm{~nm}$ and $631.0 \mathrm{~nm}$ is almost equal but the increase in the intesity of $644.0 \mathrm{~nm}$ band is stronger than that for $631.0 \mathrm{~nm}$. This

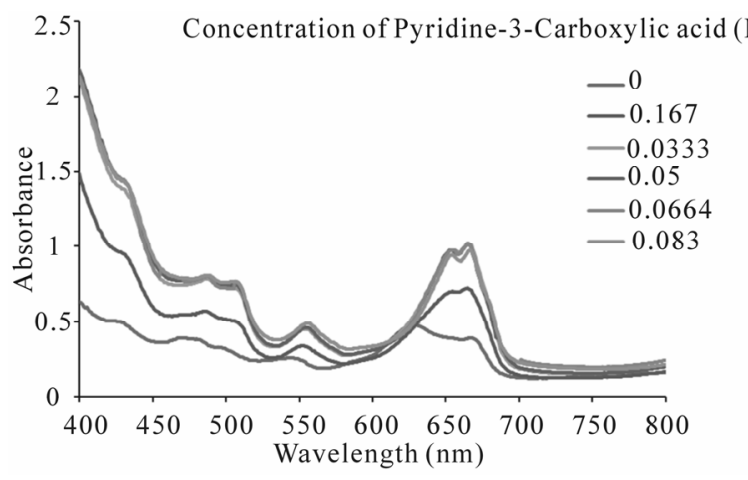

Figure 2. UV visible absorption spectrum of uranium(IV)pyridine-3-carboxylic acid complex with constant metal concentration of $0.0167 \mathrm{M}$ and varying ligand concentration. indicates that in the complex the largest decrease in transition energy occurs for the transition between the ground level ${ }^{3} \mathrm{H}_{4}$ and ${ }^{1} \mathrm{G}_{4}$. The bathochromic shift and an increase in the absorption intensity indicate a more uniform distribution of electronic charge over the whole compound and that around the central ion $[7,8]$.

\subsection{IR Spectra}

The infrared spectrum of uranium(IV) complex with pyridine-3-carboxylic acid is shown in Figure 4. The characteristic infrared absorption frequencies of the ligand and complex are summed up in Table 2. In pyridine-3-carboxylic acid the major IR bands, due to the carboxylic group at 1703.0 and $1415.7 \mathrm{~cm}^{-1}$, remain almost uninterrupted in the spectra of its complex with uranium(IV). In contrast, IR spectra of these complexes exhibit considerable perturbations related to the significant vibrational frequency of the pyridine moiety of the ligand. Absorptions at 1589.2 and $1490.9 \mathrm{~cm}^{-1}$ due to $v(\mathrm{CC})$ and $v(\mathrm{CN})$ modes respectively and that of the pyridine ring vibrations at 1031.8 and $950.8 \mathrm{~cm}^{-1}$ of the uncoordinated ligand undergo significant positive shifts. These vibrational fre-

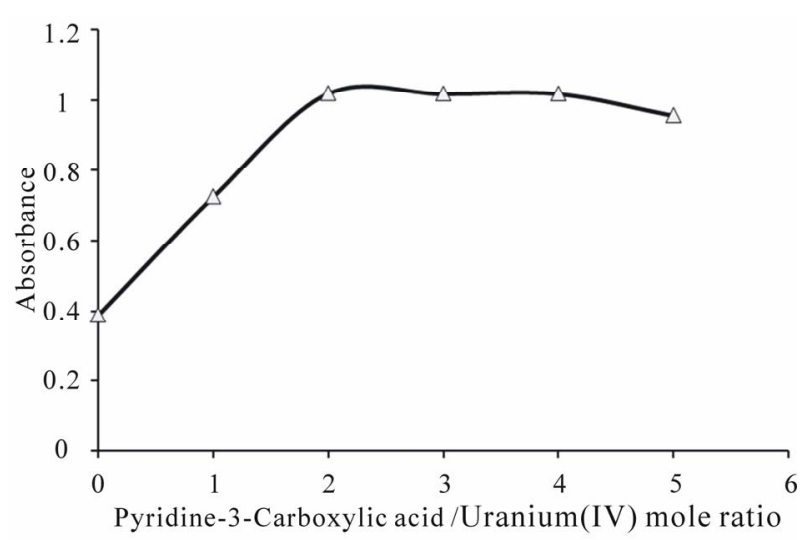

Figure 3. Mole ratio plot of uranium(IV)-pyridine-3-carboxylic acid complex at $664 \mathrm{~nm}$ wavelength.

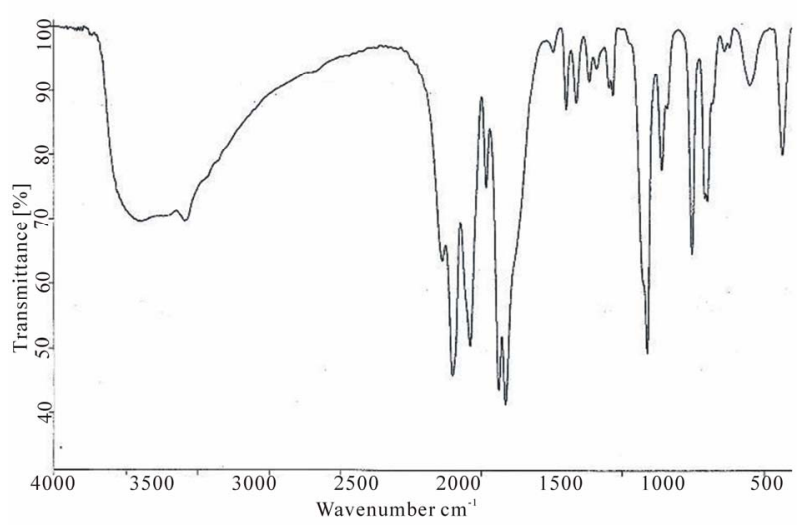

Figure 4. IR spectrum of uranium(IV) complex with pyridine-3-carboxylic acid. 
Table 1. Energy levels assigned to the absorption spectra of free uranium(IV) and its complex with pyridine-3-carboxylic acid in aqueous media.

\begin{tabular}{ccccccccc}
\hline & \multicolumn{3}{c}{ Uranium(IV) Solution in the Absence of Ligand } & \multicolumn{3}{c}{ Solution of Uranium(IV)-Pyridine-3-Carboxylic Acid Complex } \\
\hline Transitons & $\lambda(\mathrm{nm})$ & $E(\mathrm{eV} /$ molecule $)$ & Abs. & $\varepsilon\left(\mathrm{M}^{-1} \cdot \mathrm{cm}^{-1}\right)$ & $\lambda(\mathrm{nm})$ & $E(\mathrm{eV} / \mathrm{molecule})$ & $\mathrm{Abs.}$ & $\varepsilon\left(\mathrm{M}^{-1} \cdot \mathrm{cm}^{-1}\right)$ \\
\hline${ }^{3} \mathrm{H}_{4}{ }^{-} \mathrm{G}_{4}$ & 644.0 & 1.924 & 0.412 & 19.951 & 665.0 & 1.864 & 1.025 & 61.377 \\
${ }^{3} \mathrm{H}_{4}{ }^{-} \mathrm{D}_{2}$ & 631.0 & 1.964 & 0.476 & 21.614 & 654.5 & 1.893 & 0.979 & 58.622 \\
${ }^{3} \mathrm{H}_{4}{ }^{-} \mathrm{P}_{1}$ & 546.0 & 2.270 & 0.260 & 11.857 & 554.0 & 2.237 & 0.455 & 27.245 \\
${ }^{3} \mathrm{H}_{4}{ }^{-} \mathrm{I}_{6}$ & 471.0 & 2.632 & 0.395 & 17.946 & 486.5 & 2.548 & 0.786 & 47.066 \\
${ }^{3} \mathrm{H}_{4}{ }^{-} \mathrm{P}_{2}$ & 427.0 & 2.903 & 0.505 & 24.665 & - & - & - & - \\
\hline
\end{tabular}

uency shifts (Table 2) show decisively that coordination of the ligand takes place via its pyridine ring nitrogen atom to the metal ion alone. It can be concluded that the ligand is acting as a monodentate entity [9-11].

\subsection{Magnetic Susceptibility}

The results of magnetic susceptibility measurements are summarized in Table 3. The $\mu_{\text {eff }}$ value, of the synthesized complex at room temperature, was estimated using Curie law. The difference in experimental value from the value calculated assuming spin-only magnetic moment, implying that the magnetic moments are not isolated. These do interact with the adjacent centers, as might be expected if magnetic dilutions are not adequate [12].

\subsection{Electrochemical Studies}

The cyclic voltammograms of uranium(IV)-pyri-dine-3carboxylic acid complex $\left(5 \mathrm{e}^{-}-3 \mathrm{M}\right)$ in aqueous media (2 $\mathrm{M} \mathrm{HClO}_{4}$ ) at different scan rates are shown in Figure 5. At $50 \mathrm{mV} / \mathrm{s}$ scan rate of the anodic and cathodic peaks appear at $1.299 \mathrm{~V}$ and $1.029 \mathrm{~V}$ respectively.

The complex exhibits a pair of cathodic and anodic waves. The anodic peak shifts somewhat towards positive side and cathodic peak moves towards negative side with the raise in scan rate (Table 4). The values of peak potential separation $\left(E_{p A}-E_{p C}\right)$ are greater than the theoretical value $(0.059 \mathrm{~V})$ for the reversible one electron transfer process. It was also observed that separations between peak potentials increases with the increase in scan rate (Figure 6) are the indicative of charge transfer kinetics [13]. The values for $\left(E_{p A}+E_{p C}\right) / 2$ remain constant up to two decimal places, regardless of the scan rate with exceptions. In addition to that the anodic peak currents vary linearly with the square root of the scan rate (Figure 7). These results lead to the conclusion that the complexes of uranium(IV) oxidized quasi-reversibly to uranium(V) species at Platinum electrode [14].

The ratio of cathodic to the anodic peak current $I_{p C} / I_{p A}$ is less than 1 and the ratio $I_{p A} / v^{1 / 2}$ decreases with scan
Table 2. IR assignments for uranium(IV) complex with pyridine-3-carboxylic acid.

\begin{tabular}{|c|c|c|}
\hline \multicolumn{2}{|c|}{ Infrared Absorption of } & \multirow{2}{*}{$\begin{array}{c}\text { Approximate } \\
\text { description of } \\
\text { the vibrational } \\
\text { mode }\end{array}$} \\
\hline $\begin{array}{c}\text { Free } \\
\text { pyridine-3-carboxylic acid }\end{array}$ & $\begin{array}{c}\text { Uranium(IV) } \\
\text { complex with } \\
\text { pyridine-3-carboxylic acid }\end{array}$ & \\
\hline 1703.0 & 1700.5 & $v\left(\mathrm{COO}^{-}\right)$ \\
\hline- & 1635.0 & $v(\mathrm{CC})$ \\
\hline 1589.2 & 1601.0 & $v(\mathrm{CC})$ \\
\hline \multirow{2}{*}{1490.9} & 1537.5 & $v(\mathrm{CC}, \mathrm{CN})$ \\
\hline & 1480.8 & $V(\mathrm{CC}, \mathrm{CN})$ \\
\hline \multirow{2}{*}{1415.7} & 1436.8 & $V(\mathrm{CC}, \mathrm{CN})$ \\
\hline & 1414.0 & $v\left(\mathrm{COO}^{-}\right)$ \\
\hline 1296.1 & 1243.7 & $\beta(\mathrm{CH})$ \\
\hline 1180.4 & 1195.1 & $\beta(\mathrm{CH})$ \\
\hline 1112.9 & 1160.1 & $\beta(\mathrm{CH})$ \\
\hline 1085.8 & 1114.5 & $\beta(\mathrm{CN})$ \\
\hline 1031.8 & 1088.6 & Ring breathing \\
\hline 950.8 & 1031.4 & Ring breathing \\
\hline 808.1 & 861.7 & $\gamma(\mathrm{CH})$ \\
\hline 746.4 & 755.5 & $\gamma(\mathrm{CH})$ \\
\hline 688.5 & 700.9 & $\varphi(\mathrm{CC})$ \\
\hline- & 437.7 & $v(\mathrm{MN})$ \\
\hline
\end{tabular}

Table 3. Magnetic parameters for uranium(IV)-pyridine3-carboxylic acid complex.

\begin{tabular}{lccccc}
\hline$M^{x} f^{n}$ & $\mu_{\mathrm{so}}{ }^{\mathrm{a}}=[n(n+2)]^{1 / 2}$ & $\mu_{\mathrm{eff}}^{\mathrm{b}}=\left(8 \lambda_{m} T\right)^{1 / 2}$ & $T(\mathrm{~K})$ & $n^{\mathrm{c}}$ (cal.) & $n$ (Theory) \\
\hline $\mathrm{U}^{+4} f^{2}$ & 2.67 & 2.40 & 304 & 1.58 & 2 \\
\hline
\end{tabular}

${ }^{\mathrm{a}} \mu_{\mathrm{so}}$ is spin-only magnetic moment. ${ }^{\mathrm{b}} \mu_{\text {eff }}$ is an experimental effective magnetic moment calculated assuming curie behavior. ${ }^{\mathrm{c}}$ The number of unpair electrons per uranium ion calculated from the values of $\mu_{\mathrm{eff}}$ using $\mu=[n(n+2)]^{1 / 2}$. 
Table 4. Cyclic voltammetric data obtained at Pt electrode corresponding to the oxidation of uranium(IV)-pyridine-3carboxylic acid complex in $2 \mathrm{M} \mathrm{HClO}_{4}$ and $\mathrm{NaClO}_{4}$ as an electrolyte.

\begin{tabular}{ccccccccccc}
\hline $\begin{array}{c}\text { Scan rate } \\
(\mathrm{V} / \mathrm{s})\end{array}$ & $E_{p A}(\mathrm{~V})$ & $E_{p C}(\mathrm{~V})$ & $E_{P a}-E_{p C}(\mathrm{~V})$ & $E_{p A / 2}(\mathrm{~V})$ & $E_{p A}-E_{A / 2}(\mathrm{~V})$ & $I_{p A}(\mu \mathrm{A})$ & $I_{p C}(\mu \mathrm{A})$ & $I_{p C} / I_{p A}$ & $\begin{array}{c}\left(E_{p A}+E_{p C}\right) / 2 \\
(\mathrm{~V})\end{array}$ \\
\hline 0.02 & 1.296 & 1.051 & 0.245 & 1.191 & 0.105 & 0.6287 & 0.5501 & 0.8007 & 1.173 \\
0.05 & 1.3 & 1.031 & 0.269 & 1.196 & 0.104 & 0.9736 & 0.8975 & 0.9218 & 1.165 \\
0.1 & 1.305 & 1.026 & 0.279 & 1.199 & 0.106 & 1.264 & 1.254 & 0.9921 & 1.165 \\
0.15 & 1.317 & 1.017 & 0.3 & 1.209 & 0.108 & 1.573 & 1.57 & 0.9981 & 1.167 \\
0.2 & 1.32 & 1.018 & 0.302 & 1.21 & 0.11 & 1.815 & 1.814 & 0.9994 & 1.169 \\
0.25 & 1.313 & 1.016 & 0.297 & 1.211 & 0.102 & 1.958 & 1.9578 & 0.9998 & 1.164 \\
0.3 & 1.325 & 1.014 & 0.311 & 1.213 & 0.112 & 2.176 & 2.176 & 1 & 1.169 \\
0.35 & 1.329 & 1.011 & 0.318 & 1.216 & 0.113 & 2.295 & 2.295 & 1 & 1.17 \\
0.4 & 1.323 & 1.008 & 0.315 & 1.218 & 0.105 & 2.496 & 2.496 & 1 & 1.165 \\
0.45 & 1.326 & 1.007 & 0.319 & 1.219 & 0.107 & 2.588 & 2.588 & 1 & 1.166 \\
0.5 & 1.35 & 1.005 & 0.345 & 1.221 & 0.129 & 2.755 & 2.755 & 1.177 \\
\hline
\end{tabular}

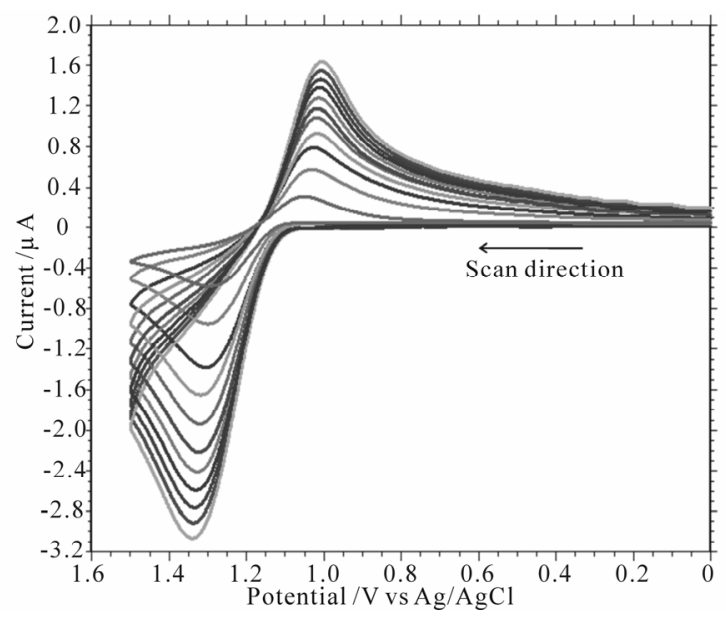

Figure 5. Cyclic voltammograms at Pt electrode corresponding to the oxidation of uranium(IV)-pyridine-3-carboxylic acid complex (Conc. $=5 \mathrm{e}-3 \mathrm{M}$ ) at scan rates from $20 \mathrm{mV} / \mathrm{s}$ to $500 \mathrm{mV} / \mathrm{s}$ in $2 \mathrm{M} \mathrm{HClO}_{4}$ and $\mathrm{NaClO}_{4}$ as an electrolyte; Temperature $=305 \mathrm{~K}$.

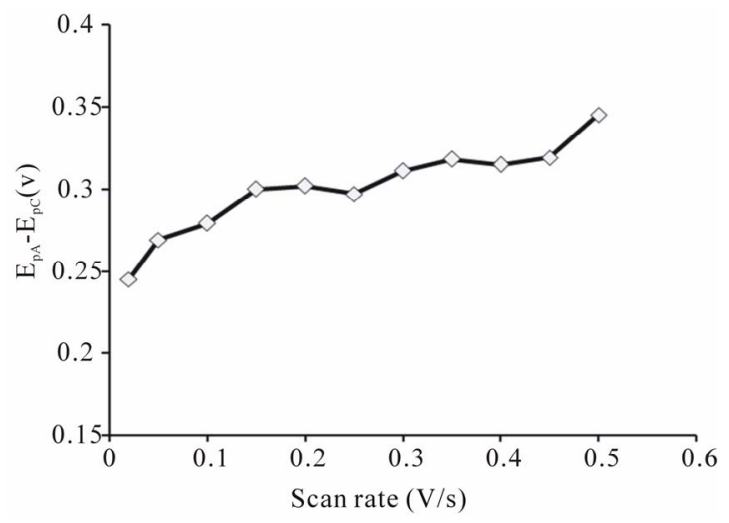

Figure 6. Variation of peak potential separation of uranium(IV)-pyridine-3-carboxylic acid complex with the scan rate. rate (Figures 8 and 9). These observations lead to an assumption of an ECE mechanism. The U(V) species formed by the oxidation of U(IV) is unstable and disproportionates into $\mathrm{U}(\mathrm{IV})$ and $\mathrm{U}(\mathrm{VI})$. No reduction current due to U(VI) species was observed [15].

$$
\begin{aligned}
& \mathrm{U}(\mathrm{IV}) \leftrightarrow \mathrm{U}(\mathrm{V})+e^{-} \\
& 2 \mathrm{U}(\mathrm{V}) \rightarrow \mathrm{U}(\mathrm{IV})+\mathrm{U}(\mathrm{VI})
\end{aligned}
$$

\subsubsection{Determination of Diffusion Coefficient}

The diffusion coefficient of the synthesized complex was calculated using Randles-Sevcik equation [16].

$$
I_{p}=0.4463(n F)^{3 / 2}(R T)^{-1 / 2} A C D_{o}^{1 / 2} v^{1 / 2}
$$

where $I_{p}$ is the peak current (in amperes), $n$ is the number of electrons transfer in the reaction, $F, R$ and $T$ have their usual meanings, $A$ is the surface area of the electrode $\left(0.0314 \mathrm{~cm}^{2}\right.$ in this case), $C$ is the concentration (in mole/ $\mathrm{cm}^{3}$ ), $D_{o}$ is the diffusion coefficient (in $\mathrm{cm}^{2} / \mathrm{s}$ ) and $v$ is the scan rate (in $\mathrm{V} / \mathrm{s}$ ).

The system seems not to be reversible but quasi-reversible. The above equation is verified in Figure 7, wherein the current was not only controlled by diffusion but also by charge transfer kinetics. The value of $D_{o}$, calculated from the slope of plot $I_{p C}$ vs $v^{1 / 2}$ (Figure 7) is equal to $3.741 \mathrm{e}-6 \mathrm{~cm}^{2} \cdot \mathrm{s}^{-1}$.

\subsubsection{Determination of Heterogeneous Electron Transfer Rate Constant}

The heterogeneous electron transfer rate constant " $k_{s}$ " was calculated by using the following equation [17].

$$
k_{s}=2.18\left[\frac{\beta D_{o} n F v}{R T}\right]^{1 / 2} \exp \left[\frac{-\beta^{2} n F}{R T}\left(E_{p A}-E_{p C}\right)\right]
$$




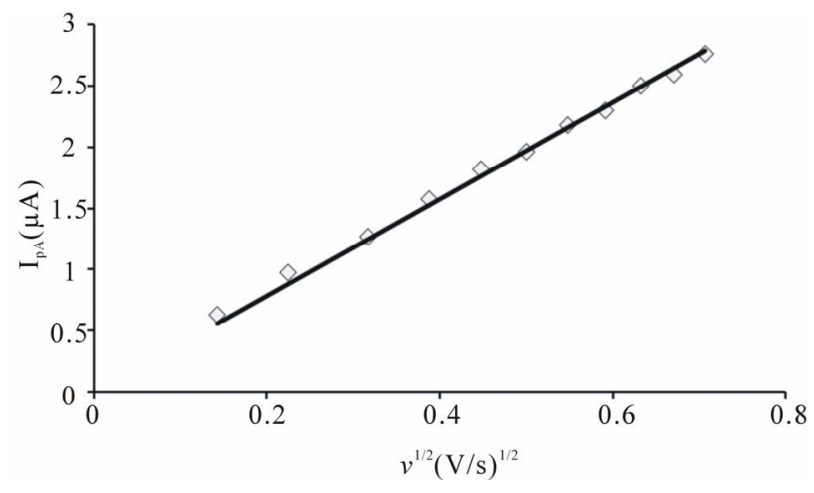

Figure 7. Variation of anodic peak current of uranium(IV)pyridine-3-carboxylic acid complex with the square root of scan rate.

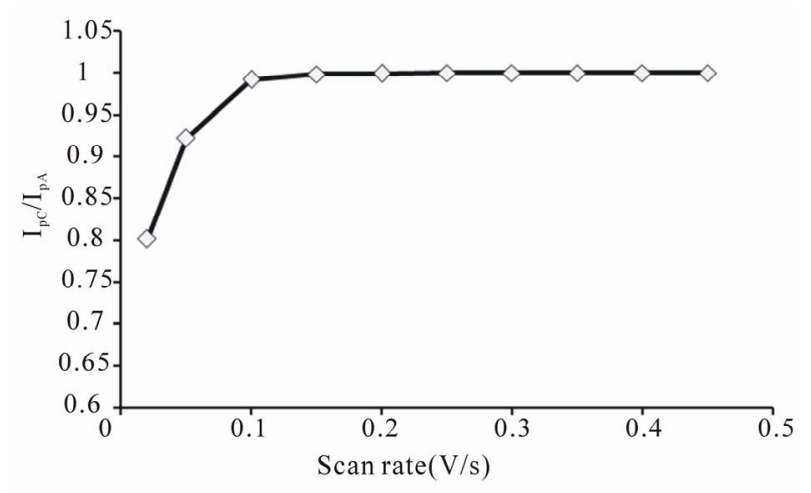

Figure 8. Variation of peak current ratio of uranium(IV)pyridine-3-carboxylic acid complex with scan rate.

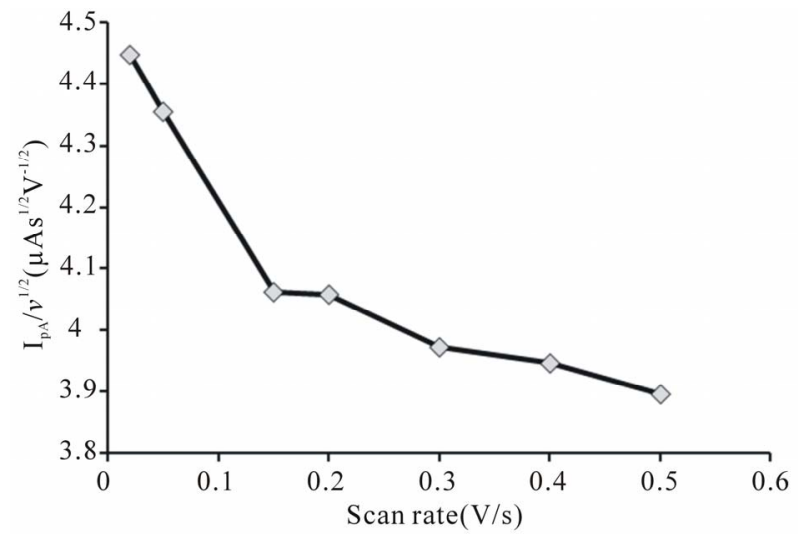

Figure 9. Variation of peak current function of uranium (IV)-pyridine-3-carboxylic acid complex with scan rate.

Where $\beta$ is the dimensionless parameter known as electron transfer coefficient, $D_{o}$ the diffusion coefficient of the oxidized species in $\mathrm{cm}^{2} / \mathrm{s}, n$ the number of electrons transferred, $v$ the scan rate, $\left(E_{p A}-E_{p C}\right)$ the peak separation and $F, R$ and $T$ have their usual meanings. Assuming the value of 0.5 for $\beta$ the value of heterogeneous electron transfer rate constant " $k_{s}$ ", at $50 \mathrm{mV} / \mathrm{s}$, was calculated to be $1.25 \mathrm{e}^{-5} \mathrm{~cm} \cdot \mathrm{s}^{-1}$.

\subsubsection{Estimation of Thermodynamic Parameters}

Evaluation of thermodynamic parameters were made by calculating heterogeneous rate constants $\left(k_{s}\right)$, at various temperatures (Table 5). The increasing value of heterogeneous rate constant with increase in temperature, is an indication that oxidation of uranium(IV) at Platinum working electrode is an endothermic process. Following equations were used to estimate thermodynamic parameters.

$$
k_{s}=Z_{h e t} \exp \left[\frac{-\Delta G^{*}}{R T}\right]
$$

Above equation can be rewrite as

$$
\ln \left(\frac{k_{s}}{Z_{\text {het }}}\right)=\frac{-\Delta G^{*}}{R T}
$$

$$
\text { As } \Delta G^{*}=\Delta H^{*}-T \Delta S^{*}
$$

Hence, the expression can be modified as

$$
\ln \left(\frac{k_{s}}{Z_{\text {het }}}\right)=\frac{-\Delta H^{*}}{R T}+\frac{\Delta S^{*}}{R}
$$

where $Z_{\text {het }}$ is the collision number for the heterogeneous electron transfer process and by using the equation $Z_{\text {het }}=\left(\frac{R T}{2 \pi M}\right)^{1 / 2}$, its value can be determined at a particular temperature, where $M$ is the molecular weight of the reacting species, $R$ is the general gas constant and $T$ is the temperature in Kelvin.

The value of $-\Delta G_{298}^{*}$, an apparent free energy of activation, at $298 \mathrm{~K}$ were calculated using the equation.

$$
\Delta G^{*}=\Delta H^{*}-T \Delta S^{*}
$$

The value of $\Delta H^{*}$ and $\Delta S^{*}$ for each of the synthesized complex were evaluated from the slope and intercept of the plots of $\ln \left(\frac{k_{s}}{Z_{h e t}}\right)$ versus $1 / T$ (Figure 10).

The values of $\Delta H^{*}\left(\mathrm{~kJ} \cdot \mathrm{mol}^{-1}\right), \Delta S^{*}\left(\mathrm{~J} \cdot \mathrm{mol}^{-1} \cdot \mathrm{K}^{-1}\right)$

Table 5. Kinetic data for uranium(IV) ion at different temperatures when complexed with nicotinic acid.

\begin{tabular}{cc}
\hline Temperature $(\mathrm{K})$ & $\begin{array}{r}\text { Heterogeneous rate constants } \\
\left(k_{s}\right) \times 10^{4}\left(\mathrm{~cm} \cdot \mathrm{s}^{-1}\right)\end{array}$ \\
\hline 298 & 4.26 \\
303 & 4.64 \\
308 & 5.28 \\
313 & 5.96 \\
318 & 6.49 \\
323 & 6.75 \\
\hline
\end{tabular}




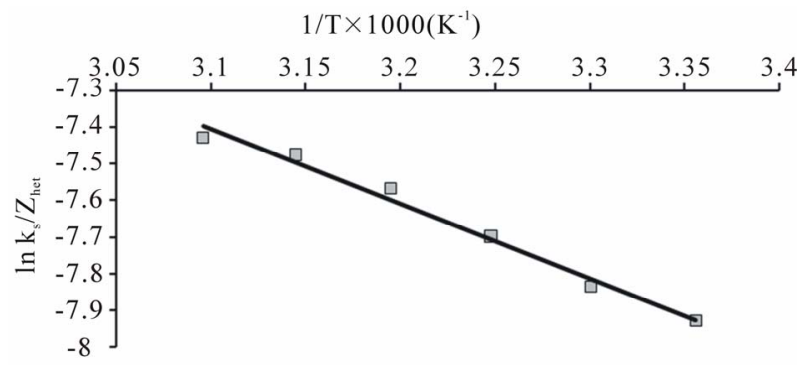

Figure 10. Plot of $\ln \left(k_{s} / Z_{h e t}\right)$ vs $1 / T$ for the evaluation of thermodynamic parameters for the oxidation of uranium (IV) when complexed with nicotinic acid at Pt electrode.

and $\Delta G_{298}^{*}\left(\mathrm{~kJ} \cdot \mathrm{mol}^{-1}\right)$ for the synthesized complex are found to $16.97,-60.71$ and 35.06 respectively. The oxidation of uranium(IV) is a non-spontaneous and endothermic process, as specified by positive values of $\Delta H^{*}$ and $-\Delta G_{298}^{*} \quad[18-20]$.

\section{Conclusions}

The study of uranium(IV) complex with pyridine-3-carboxylic acid shows that the ligand coordinates only via its pyridine ring nitrogen with metal to ligand ratio 1:2. Ahuja et al. also observed complexation of the same pattern while complexing this ligand with uranyl ion [5].

The oxidation of the synthesized complex of uranium (IV) leads to the formation of uranium(V) species. Following the oxidation process, disproportionation of uranium (V) takes place, representing an ECE mechanism. Moreover, the oxidation of uranium(IV) at platinum working electrode is an endothermic and non-spontaneous process.

\section{REFERENCES}

[1] M. Tamada, N. Seko and F. Yoshii, "Application of Radiation-Graft Material for Metal Adsorbent and Crosslinked Natural Polymer for Healthcare Product," Radiation Physics and Chemistry, Vol. 71, No. 1-2, 2004, pp. 221-225. doi:10.1016/j.radphyschem.2004.03.044

[2] P. G. Barbano and L. Rigali, "Spectrophotometric Determination of Uranium in Sea Water after Extraction with Aliquat-336," Analytica Chimica Acta, Vol. 96, No. 1, 1978, pp. 199-201. doi:10.1016/S0003-2670(01)93415-4

[3] T. A. Sullens, R. A. Jensen, T. Y. Shvareva and T. E. Albrecht-Schmitt, "Cation-Cation Interactions between Uranyl Cations in a Polar Open-Framework Uranyl Periodate," Journal of the American Chemical Society, Vol. 126, No. 9, 2004, pp. 2676-2677. doi:10.1021/ja031695h

[4] M. J. Sarsfield and M. Helliwell, "Extending the Chemistry of the Uranyl Ion: Lewis Acid Coordination to a UO Oxygen," Journal of the American Chemical Society, Vol. 126, No. 4, 2004, pp. 1036-1037. doi:10.1021/ja039101y

[5] S. A. Ishar, R. Singh and S. Rangarajalu, "Nicotinic Acid Complexes with Uranyl Salts," Transition Metal Chemis- try, Vol. 3, No. 1, 1978, pp. 193-195. doi:10.1007/BF01393544

[6] I. I. Naqvi, Journal of Pakistan Psychiatric Society, Vol. 2, 1980, p. 35.

[7] C. K. Jørgenson, "The Nephelauxetic Effect in Uranium (IV) Compounds," Chemical Physics Letters, Vol. 87, No. 4, 1982, pp. 320-323. doi:10.1016/0009-2614(82)83594-X

[8] B. Jeżowska-Trazebiatowska and K. Bukietyńska, "The Electronic Structure of Uranium (IV) in Complex Compounds-I Comparison of the Absorption Spectra of Uranium (IV) and Praseodymium (III) Compounds," Journal of Inorganic and Nuclear Chemistry, Vol. 19, No. 1-2, 1961, pp. 38-42. doi:10.1016/0022-1902(61)80043-2

[9] P. Moscibrode, H. Baranska, T. Drapala and W. Lewandowski, "Effect of Sodium and Lanthanides (III) on the Aromatic System of Nicotinic, Benzoic and Salicylic Acid," Journal of Molecular Structure, Vol. 267, 1992, pp. 255-260. doi:10.1016/0022-2860(92)87041-S

[10] S. Chattopadhyay and S. K. Brahma, Spectrochimica Acta, Vol. 49A, No. 4, 1993, pp. 589-597.

[11] R. Singh and R. S. S. Rao, "Synthesis and Characterization of Divalent Manganese, Cobalt, Nickel, Copper and Zinc Complexes with Nicotinic Acid," Journal of Molecular Structure, Vol. 71, 1981, pp. 23-30. doi:10.1016/0022-2860(81)85100-9

[12] Magnetic Susceptibility Balance Instructional Manual, Magway, England, 2001.

[13] M. S. Rahman, H. M. N. Akhtar, P. K. Bakshi and M. Q. Ehsan, Journal of Saudi Chemical Society, Vol. 11, No. 2, 2007, pp. 277-286.

[14] P. Giridhar, K. A. Venkatesan, T. G. Srinivasan and P. R. Vasudeeva Rao, "Electrochemical Behavior of Uranium (VI) in 1-Butyl-3-Methylimidazolium Chloride and Thermal Characterization of Uranium Oxide Deposit," Electrochimica Acta, Vol. 52, No. 9, 2007, pp. 3006-3012. doi:10.1016/i.electacta.2006.09.038

[15] D. Hauchard, M. Cassir and J. Chivot, "Electrochemical Study of Uranium(IV) and Uranium(IV) Organometallic Compounds in Tetrahydrofuran by Means of Conventional Microelectrodes and Ultramicroelectrodes: Part I. Application to the $\mathrm{Na}(\mathrm{Hg})$ Reduction of $\mathrm{Cp}_{3} \mathrm{UCl}(\mathrm{Cp}=\eta$ $\left.\mathrm{C}_{5} \mathrm{H}_{5}\right)$," Journal of Electroanalytical Chemistry, Vol. 313, No. 1-2, 1991, pp. 227-241. doi:10.1016/0022-0728(91)85182-O

[16] A. J. Bard and L. R. Faulkner, "Electrochemical Methods-Fundamentals and Applications," Wiley, New York, 1980.

[17] R. J. Klingler and J. K. Kochi, "Electron-Transfer Kinetics from Cyclic Voltammetry. Quantitative Description of Electrochemical Reversibility," Journal of Physical Chemistry, Vol. 85, No. 12, 1981, pp. 1731-1741. doi: $10.1021 / \mathrm{j} 150612 \mathrm{a} 028$

[18] A. S. A. Khan, R. Ahmed and M. L. Mirza, "Kinetics and Electrochemical Studies of Uranium in Acetate and Formate Media by Cyclic Voltammetry," Radiochim Acta, Vol. 95, No. 12, 2007, pp. 693-699. doi:10.1524/ract.2007.95.12.693 
[19] A. S. A. Khan, R. Ahmed and M. L. Mirza, Journal of the Chemical Society of Pakistan, Vol. 30, 2008, pp. 170177.

[20] R. A. Marcus, "On the Theory of Electron-Transfer Reac- tions. VI. Unified Treatment for Homogeneous and Electrode Reactions" Journal of Chemical Physics, Vol. 43, No. 2, 1965, pp. 679-701. doi:10.1063/1.1696792 